\title{
Argamassas com resíduos para revestimento isolante térmico de parede pré-moldada de concreto
}

\author{
(Mortars with wastes for thermal insulation rendering \\ of precast concrete wall)
}

\author{
P.M.Passos ${ }^{1 *}$, H. Carasek ${ }^{1}$ \\ ${ }^{1}$ Universidade Federal de Goiás, Escola de Engenharia Civil e Ambiental, PPG-GECON, Goiânia, GO, Brasil
}

\begin{abstract}
Resumo
Inserido em contexto de preocupações com desempenho térmico e sustentabilidade na construção civil, este trabalho visou desenvolver argamassas com propriedades isolantes térmicas para revestimento de paredes pré-moldadas de concreto. O programa experimental avaliou três dosagens de argamassa com resíduo de poliestireno expandido (EPS) e resíduo da produção de placas isolantes termoacústicas (contendo fibras de lã de rocha, lã de vidro e vermiculita expandida), e uma dosagem de referência. Caracterizou-se o resíduo por meio de MEV, DRX, FRX e picnometria a gás hélio. Efetuaram-se ensaios das argamassas (estado fresco e endurecido), do revestimento aplicado (resistência de aderência e permeabilidade à água) e avaliação do desempenho térmico do sistema de vedação. Os resultados demonstraram potencial das argamassas com resíduos como revestimento isolante (valores de condutividade térmica até quatro vezes inferiores aos de referência). A inserção do resíduo com fibras otimizou propriedades mecânicas das argamassas e do revestimento (resistência à tração e de aderência).
\end{abstract}

Palavras-chave: revestimento, argamassa, resíduos, EPS, fibra, desempenho térmico.

\begin{abstract}
In a context of thermal performance and sustainable development, this paper aimed to develop rendering mortars with thermal insulating properties for the precast concrete wall. The experimental program consisted in evaluating three mix proportions with expanded polystyrene (EPS) waste and a finishing process waste of thermal insulating panels (rock wool, glass wool and vermiculite) and a standard mortar. Waste was characterized by SEM, XRD, XRF spectroscopy and helium gas pycnometry. The characterization was performed with tests in mortars (fresh and hardened state) and tests of a precast concrete wall plastered with mortar (bond strength and water permeability). In addition, thermal performance evaluation was carried out showing as a main advantage the thermal insulation of lightweight mortars with wastes compared to common mortars (thermal conductivity four times lower). The addition of waste with fibers resulted in better mechanical properties for mortars and rendering (tensile strength and bond strength).
\end{abstract}

Keywords: rendering, mortar, waste, EPS, fiber, thermal performance.

\section{INTRODUÇÃO}

As discussões sobre eficiência energética no início dos anos 2000, em que ocorreram crises de fornecimento, fizeram surgir políticas públicas sobre o consumo racional de energia elétrica e legislação específica sobre o tema (Lei $n^{\circ}$ 10295/01 e o Decreto Lei $\left.n^{\circ} 4059 / 01\right)$. Originouse deste debate, inclusive, metodologia de classificação das edificações segundo critérios de conservação e uso racional de energia, chamada de etiquetagem $[1,2]$. O setor residencial é responsável por parte importante do consumo energético brasileiro (23\%) e neste segmento destaca-se o consumo em sistemas de condicionamento de ar, responsáveis na média nacional por $20 \%$ dos gastos com eletricidade [3]. Nesse sentido, melhorar propriedades térmicas dos envelopes das habitações é uma solução

*paulompengc@gmail.com razoável para reduzir o consumo energético de soluções ativas de condicionamento de ar. Ressalta-se que os revestimentos de argamassa convencionais podem ser responsáveis por até $30 \%$ do isolamento térmico do sistema de vedação, a depender da sua espessura e composição, bem como das características da parede de vedação [4]. Assim, é possível compreender a influência da envoltória das edificações no desempenho térmico e nas condições de habitabilidade das edificações, uma vez que esta se relaciona com o conforto térmico proporcionado aos usuários [5]. Em vista disso, o emprego de argamassas leves pode, por meio da redução de parâmetros de condutividade, representar uma solução à medida que se aumenta a resistência térmica do sistema de vedação [6]. Acrescenta-se a preocupação com o desempenho das edificações, que foi expressa recentemente a partir de processos normativos que resultaram na publicação da norma ABNT NBR 15575:2013. O escopo da norma é apresentar requisitos e critérios de verificação dos níveis 
mínimos de desempenho das edificações; especificamente a Parte 4 dessa norma apresenta os requisitos para os sistemas de vedações verticais internas e externas [7].

A sustentabilidade, que está também relacionada à eficiência energética, é outro ponto que tem permeado as diretrizes de desenvolvimento visando não se prejudicar as gerações futuras. A construção civil, nesse cenário de preocupações que não estão sendo plenamente atendidas, como a eficiência energética e o desempenho, tem contribuído para a diminuição do déficit habitacional brasileiro, como comprovam os dados de estimativas de déficit de habitações [8]. Entretanto, é uma atividade que gera impacto significativo por consumir grande quantidade de matéria-prima e gerar um volume considerável de resíduos $[9,10]$. A geração de resíduos é condição inevitável do uso de materiais, os quais ao fim do ciclo de vida devem ter correta destinação. O reaproveitamento de resíduos maximiza a utilização da energia incorporada na obtenção de um material, nas etapas de extração, manufatura e transporte. O poliestireno expandido (EPS), por exemplo, consome 88,6 MJ/kg produzido [11]. Se aplicado em embalagens, esta energia incorporada é subutilizada já que o ciclo de vida é muito curto, gerando rapidamente resíduos com pouca massa, mas que ocupam grande volume em aterros sanitários. O EPS é resultado da polimerização do estireno e é reconhecido por suas características de baixa densidade e baixa condutividade térmica. Suas propriedades isolantes advêm de seu volume celular, composto por $98 \%$ de ar e $2 \%$ de poliestireno [12]. No contexto técnico, diversas pesquisas vêm sendo desenvolvidas visando a produção e o estudo de compósitos cimentícios leves com a utilização de resíduos de EPS. Em concretos, especial análise do comportamento resistência mecânica $\mathrm{x}$ densidade $\mathrm{x}$ condutividade térmica é estudada de modo a prezar o equilíbrio de requisitos de desempenho térmico e comportamento estrutural, representados por grandezas de relação inversamente proporcional $[13,14]$. A atenção à redução de propriedades físico-mecânicas e o modo de ruptura de compósitos cimentícios com agregados leves utilizando modelagem com elementos finitos, por exemplo, demonstram os caminhos preferenciais de rupturas e propagação de fissuras internas através dos agregados leves [15]. No estudo de argamassas, resultados de condutividade térmica com valores entre 0,33 e $0,01 \mathrm{~W} / \mathrm{mK}$ foram obtidos a partir de argamassas com densidade aparente entre 1290 e $341 \mathrm{~kg} / \mathrm{m}^{3}$, entretanto, sem a utilização de emulsões poliméricas adesivas os proporcionamentos com substituição de areia por EPS não obtiveram aderência ao substrato [16-21]. Sob o mesmo ponto de vista técnico, em busca de soluções com argamassas isolantes, análises da microestrutura [17], avaliações com imagens térmicas de sistemas de vedação, caracterização mecânica e estudos de durabilidade de argamassas com EPS demonstram potencial de utilização e de isolamento térmico com a inconveniente carência de resistência mecânica [17-21]. Em situação análoga ao EPS, outros materiais subutilizados são os resíduos de lã de rocha e lã de vidro (ambas fibras cerâmicas), além de vermiculita expandida (minério com baixa massa específica), que podem ser oriundos da fabricação de componentes de isolamento térmico. Para esses resíduos ainda não há uma aplicação certa e, portanto, eles geralmente são destinados à disposição final em aterros ou se acumulam em depósitos de indústrias [9].

Nesta conjuntura de preocupações de eficiência energética, desempenho térmico, reaproveitamento de resíduos subutilizados e contexto técnico, o presente trabalho visa desenvolver uma argamassa para revestimento com propriedades isolantes térmicas, de aderência e resistência mecânica compatíveis com requisitos de utilização. A partir do cenário exposto desenvolveram-se argamassas utilizando resíduos de EPS e resíduos da produção de placas isolantes térmicas (composto de lã de rocha, lã de vidro e vermiculita expandida - LV). Desta forma, apresenta-se uma utilização nobre para dois resíduos existentes, sendo que para os resíduos de placas isolantes termoacústicas (LV) ainda não se tinha uma proposta de aplicação. O trabalho tem, então, como objetivos específicos: 1) caracterizar detalhadamente o resíduo LV, uma vez que não foram encontrados trabalhos que apresentassem tal caracterização; além de 2) qualificar o comportamento físico-mecânico e o desempenho térmico dos compósitos cimentícios desenvolvidos, avaliando-os como revestimento integrante de um sistema de vedação em parede de concreto. O desenvolvimento dessa argamassa tem como finalidade oferecer uma alternativa de revestimento de sistemas verticais de vedação externa que possibilite a otimização do desempenho térmico de habitações que utilizam o sistema executivo de paredes de concreto prémoldadas. Ainda visa apresentar uma estratégia mitigadora de impactos causados pela construção civil ao incorporar resíduos substituindo parte dos agregados das argamassas de revestimento, propiciando desta forma a redução da extração de areia natural, priorizando a proteção de recursos naturais.

\section{MATERIAIS E MÉTODOS}

O estudo baseou-se na comparação de uma argamassa convencional de referência - REF (de traço em volume 1:1:6, cimento, cal e areia) com argamassas contendo dois teores de incorporação de resíduos de EPS em substituição à areia (cerca de $80 \%$ e 90\%, E80 e E90), e de uma argamassa contendo também o resíduo do acabamento de painéis isolantes termoacústicos (E90LV), composto de lãs de vidro e de rocha além de vermiculita (LV). Aos traços com resíduos

Tabela I - Proporcionamento (traço) das argamassas, em volume.

[Table I - Proportions of mortar mix (volume).]

\begin{tabular}{lcccccc} 
Traço & Cimento & Cal & Areia & EPS & LV & Aditivo \\
\hline REF & 1 & 1,0 & 6,0 & - & - & - \\
E80 & 1 & 0,5 & 1,0 & 5,0 & - & 0,13 \\
E90 & 1 & 0,5 & 0,5 & 5,5 & - & 0,20 \\
E90LV & 1 & 0,5 & 0,5 & 5,5 & 0,5 & 0,20 \\
\hline
\end{tabular}


foi adicionado aditivo de base acrílica para promover a adesão do EPS à pasta de cimento. O proporcionamento de materiais das argamassas estudadas é apresentado na Tabela I.

O programa experimental de avaliação das argamassas envolveu a caracterização dos materiais constituintes e das argamassas no estado fresco e endurecido, além da avaliação dos revestimentos aplicados em paredes prémoldadas de concreto. Foi também realizada uma avaliação do desempenho térmico do sistema: parede de concreto revestida com as diferentes argamassas em estudo. A Fig. 1 apresenta um fluxograma desse programa. A avaliação do desempenho térmico do sistema de vedação, com base em resultados de condutividade térmica determinados experimentalmente, foi realizada após a avaliação das argamassas e revestimentos contendo resíduos. Desse modo, este programa experimental amplia a investigação dos resultados de caracterização térmica apresentados em trabalho anterior [18], assim como expande a caracterização dos constituintes das argamassas, principalmente do resíduo LV, bem como apresenta resultado de ensaios de ciclos de molhagem e secagem do revestimento para avaliação da sua durabilidade após um ano.

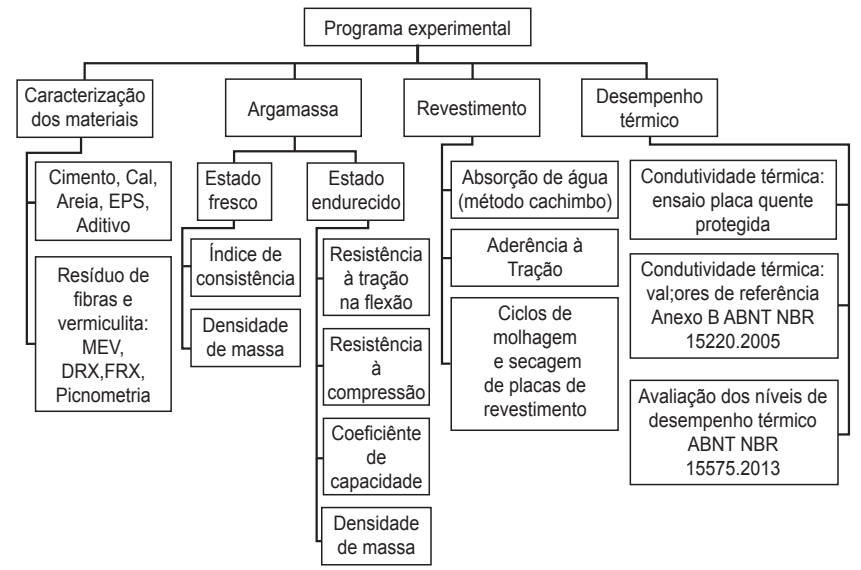

Figura 1: Fluxograma do programa experimental.

[Figure 1: Experimental flowchart.]
Materiais: o cimento utilizado foi do tipo CP V-ARI e a cal hidratada do tipo CH-I, cujas caracterizações estão resumidas nas Tabelas II e III. Como agregado foi utilizada uma areia média quartzosa, lavada, natural de leito de rio. A caracterização da areia é apresentada na Tabela IV e nas Figs. 2 e 3 . O resíduo de EPS foi obtido de material de descarte proveniente de peças de EPS de alta densidade. Esse resíduo passou por inspeção visual e posterior trituração (aspecto apresentado na Fig. 3b). O processamento do EPS foi constituído por etapa única de trituração e peneiramento com utilização de triturador mecânico (TR-200, Trapp, potência $1,5 \mathrm{HP}$ e rotação de $3600 \mathrm{rpm}$ ) e peneira de malha $5 \mathrm{~mm}$. O resíduo triturado de EPS apresentou massa específica aparente de $0,041 \mathrm{~kg} / \mathrm{dm}^{3}$. As distribuições granulométricas do EPS triturado e das composições areia natural e EPS triturado, determinadas segundo a norma ABNT NBR NM 248:2003, são apresentadas na Fig. 2. Tendo em vista não existirem parâmetros normalizados no Brasil para areias visando a produção de argamassas, apresentou-se no gráfico os limites recomendados pela ASTM C 897 para areias utilizadas em emboços e revestimentos externos. Percebeu-se que a areia natural ficou muito próxima do limite superior especificado, enquanto as partículas de EPS tiveram um comportamento bem diferente, com partículas maiores. A composição areia/EPS resultou em distribuição mais compatível com os limites recomendados, entretanto vale ressaltar que a baixa densidade do resíduo exerceu pouca influência sobre a distribuição granulométrica que avalia proporções de massa retidas pelas malhas das peneiras. A inserção do EPS triturado exerceu influência devido ao volume do material; esse tópico é discutido nos resultados. O resíduo constituído por lã de rocha, lã de vidro e vermiculita (lãs e vermiculita - LV) foi proveniente de indústria de painéis isolantes térmicos e acústicos e resultou do processo de acabamento por lixamento dos compósitos (Isoplan-Fibraroc). O resíduo continha também pequenos aglomerados de resina (cerca de $5 \%$ em volume), que é utilizada no processo industrial de montagem das placas. Dessa forma, esse resíduo foi

Tabela II - Caracterização do cimento.

[Table II - Cement characterization.]

\begin{tabular}{|c|c|c|c|c|c|c|c|c|c|c|c|}
\hline \multicolumn{6}{|c|}{ Composição química $(\%)^{1}$} & \multirow{2}{*}{$\begin{array}{c}\text { Perda ao } \\
\text { fogo }^{2}\end{array}$} & \multirow{2}{*}{$\begin{array}{l}\mathrm{CaO} \\
\text { livre }^{3} \\
\end{array}$} & \multirow{2}{*}{$\begin{array}{l}\text { Resíd. } \\
\text { insol. }\end{array}$} & \multirow{2}{*}{$\begin{array}{l}\text { Equiv. } \\
\text { alcal. }^{5}\end{array}$} & \multirow{2}{*}{$\begin{array}{l}\text { Blaine }^{6} \\
\left(\mathrm{~cm}^{2} / \mathrm{g}\right)\end{array}$} & \multirow{2}{*}{$\begin{array}{c}\# 200^{7} \\
(\%)\end{array}$} \\
\hline $\mathrm{Al}_{2} \mathrm{O}_{3}$ & $\mathrm{SiO}_{2}$ & $\mathrm{Fe}_{2} \mathrm{O}_{3}$ & $\mathrm{CaO}$ & $\mathrm{MgO}$ & $\mathrm{SO}_{3}$ & & & & & & \\
\hline 4,32 & 19,17 & 2,72 & 60,64 & 3,98 & 2,98 & 3,31 & 0,60 & 0,86 & 0,72 & 4290 & 0,04 \\
\hline
\end{tabular}

Tabela III - Caracterização da cal hidratada.

[Table III - Hydrated lime characterization.]

\begin{tabular}{ccccccc}
\hline $\begin{array}{c}\text { Anidrido } \\
\text { carbônico } \\
\mathrm{CO}_{2}\end{array}$ & $\begin{array}{c}\text { Óxidos de } \\
\text { Ca e Mg não } \\
\text { hidratados }^{1}\end{array}$ & $\begin{array}{c}\text { Óxidos totais } \\
\text { na base de não } \\
\text { voláteis }^{1}\end{array}$ & $\begin{array}{c}\text { Finura }^{2} \\
\text { peneira } \\
0,6 \mathrm{~mm}\end{array}$ & $\begin{array}{c}\text { Finura }^{2} \\
\text { peneira } \\
0,075 \mathrm{~mm}\end{array}$ & $\begin{array}{c}\text { Plasticidade }^{3} \\
(\mathrm{~mm})\end{array}$ & $\begin{array}{c}\text { Massa } \\
\text { unitária }^{4} \\
\left(\mathrm{~g} / \mathrm{cm}^{3}\right)\end{array}$ \\
\hline $4,05 \%$ & $5,96 \%$ & $97,04 \%$ & $0,26 \%$ & $9,10 \%$ & 120,75 & 0,45 \\
\hline
\end{tabular}

- ABNT NBR 6473:2003; ${ }^{2}$ - ABNT NBR 9289:2000; ${ }^{3}$ - ABNT NBR 9206:2003; ${ }^{4}$ - ABNT NBR NM 23:2001. 
Tabela IV - Caracterização da areia. [Table IV - Sand characterization.]

\begin{tabular}{cccc}
\hline $\begin{array}{c}\text { Módulo } \\
\text { de finura }\end{array}$ & $\begin{array}{c}\text { Dimensão máxima } \\
\text { característica }(\mathrm{mm})\end{array}$ & $\begin{array}{c}\text { Massa } \\
\text { específica } \\
\left(\mathrm{g} / \mathrm{cm}^{3}\right)\end{array}$ & $\begin{array}{c}\text { Teor de } \\
\text { materiais } \\
\text { pulverulentos }\end{array}$ \\
\hline 2,01 & 1,18 & 2,62 & $1,0 \%$ \\
\hline
\end{tabular}

Nota: ABNT NBR NM 248:2003/ NM 46:2003.

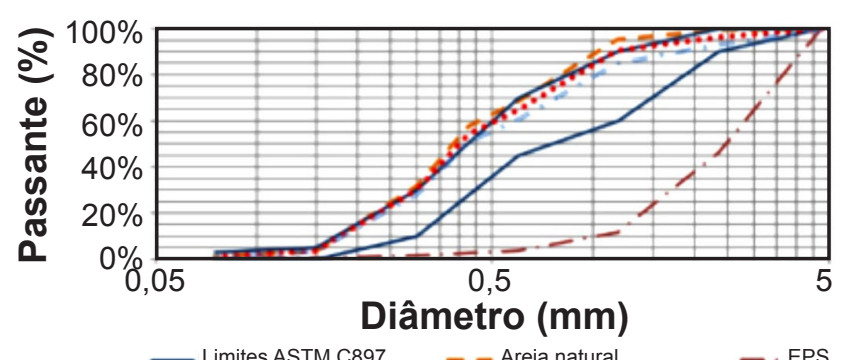

-... Composição EPS $80 \%$ Areia 20\% - - Composição EPS 90\% Areia 10\%

Figura 2: Curvas de distribuição granulométrica da areia natural e do resíduo de EPS.

[Figure 2: Particle size distribution curves of sand and EPS.]
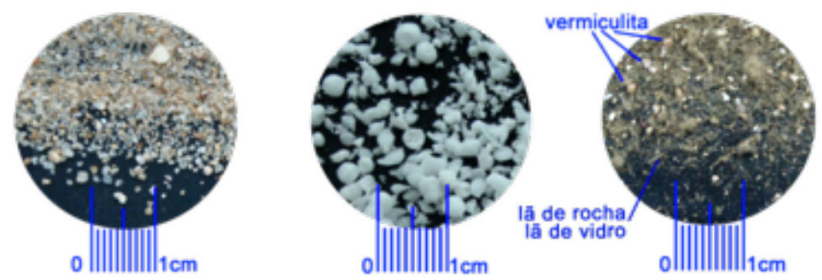

Figura 3: Imagens dos materiais utilizados: (a) areia natural; (b) resíduo de EPS triturado; e (c) resíduo de lã de rocha/lã de vidro/ vermiculita.

[Figure 3: Images of used materials: (a) sand; (b) crushed EPS; and (c) waste of rock wool, glass wool and vermiculite.]

composto por fibras de pequena dimensão (lãs de rocha e de vidro, $40 \%$ e $40 \%$ em volume) e grãos de vermiculita expandida ( $15 \%$ em volume, Fig. $3 \mathrm{c}$ ).

Para o preparo das argamassas foi empregada água da rede pública de abastecimento. Às argamassas compostas por resíduos foi adicionado também um aditivo com a finalidade de melhorar a trabalhabilidade, permitindo a mistura adequada e perfeita homogeneização do EPS, que é muito leve e não se mistura adequadamente na matriz aglomerante sem essa emulsão polimérica. Foi utilizada uma emulsão polimérica comercial de base acrílica solúvel em água (proporcionamento apresentado na Tabela I) contendo pequenas fibras de polipropileno. Esse aditivo de propriedades impermeabilizantes por hidrofugação e de melhoria da trabalhabilidade por incorporação de ar apresentou densidade de $0,85 \mathrm{~g} / \mathrm{cm}^{3}, \mathrm{pH}$ de 8,5 e teor de sólidos de $14 \%$. Os revestimentos foram aplicados sobre paredes maciças de concreto (pré-moldadas) com resistência característica de $20 \mathrm{MPa}$. As placas armadas em seu interior apresentaram as seguintes dimensões: $170 \mathrm{~cm}$ de altura, $150 \mathrm{~cm}$ de largura e $10 \mathrm{~cm}$ de espessura.
Métodos. Caracterização detalhada do resíduo do acabamento de painéis isolantes termoacústicos - LV: a caracterização dos resíduos oriundos de placas isolantes térmicas recebeu especial atenção por se tratar de material de composição desconhecida. Foram utilizadas as seguintes técnicas: i) fluorescência de raios $\mathrm{X}$ (FRX): a composição química quantitativa do resíduo foi determinada utilizandose um equipamento da Thermo Fischer Scientific, ARL Perform'X 4200; a preparação da amostra foi feita por moagem, peneiramento total em malha de abertura $0,074 \mathrm{~mm}$ e prensagem em forma de pastilha; ii) microscopia eletrônica de varredura (MEV): amostras do resíduo in natura foram observadas ao MEV utilizando-se um equipamento da Jeol,JSM-6610; a amostra foi depositada em fita de carbono de dupla face e posteriormente metalizada com ouro; as imagens foram obtidas a partir dos sinais de elétrons secundários, com uma tensão de $5 \mathrm{kV}$; no caso das fibras, foram medidos os comprimentos e os diâmetros de 25 filamentos; com a medida destes valores foi calculado o fator de forma (relação entre comprimento e diâmetro); iii) difratometria de raios $\mathrm{X}(\mathrm{DRX})$ : para a análise mineralógica qualitativa utilizou-se o equipamento da Siemens, D5000, configuração $\theta / 2 \theta$, ânodo de cobre, $40 \mathrm{kV}$ e $30 \mathrm{~mA}$, varredura com passo de $0,05^{\circ}$ e tempo por passo de $1 \mathrm{~s}$; a amostra foi preparada da mesma forma que para a análise de FRX; iv) picnometria a gás hélio: para determinar a massa específica do resíduo utilizou-se o equipamento AccuPyc II 1340, Micromeritics, com precisão decimal na quarta casa; foram realizadas 3 determinações em amostras in natura e obteve-se a média dos valores.

Preparo das argamassas: a quantidade de água em cada traço foi definida no início da pesquisa por meio de um estudo piloto que visou obter a trabalhabilidade adequada para aplicação dos revestimentos no sistema fabril de revestimento de paredes pré-moldadas (aplicação de argamassa de revestimento sobre paredes em posição horizontal). Além da avaliação visual das argamassas, foi realizado o ensaio de índice de consistência - flow table (ABNT NBR 13276:2002) em que se determinou faixa de trabalhabilidade exigida para aplicação das argamassas com resíduos EPS e LV. Obteve-se índice de consistência de $150 \pm 20 \mathrm{~mm}$ como faixa adequada para aplicação sobre os painéis pré-moldados. As argamassas utilizadas para a caracterização no estado fresco e para a moldagem dos corpos de prova foram produzidas em laboratório utilizando-se um agitador mecânico com controle de rotação (Ika, Eurostar 60 Control), provido de haste de hélice com 4 pás, com mistura durante $5 \mathrm{~min}$. Para o preparo das argamassas que foram aplicadas como revestimento às paredes de concreto e corpos de prova para demais ensaios, quando foi necessário um volume maior de argamassa, a mistura foi realizada em betoneira de eixo inclinado de capacidade de $200 \mathrm{~L}$, com mistura durante aproximadamente $6 \mathrm{~min}$. Nas duas situações garantiu-se a completa homogeneização das argamassas bem como a obtenção da trabalhabilidade adequada (determinada no estudo piloto) através da dosagem de água e de aditivo. Caracterização das argamassas: no estado 
fresco foram realizados os ensaios do índice de consistência - flow table (ABNT NBR 13276:2002) e de densidade de massa (ABNT NBR 13278:2005). No estado endurecido, as argamassas foram caracterizadas aos 28 dias quanto à densidade de massa aparente (ABNT NBR 13280:2005), coeficiente de capilaridade (ABNT 15259:2005), resistência à tração na flexão e resistência à compressão (ABNT NBR 13279:2005). A partir da curva de tensão-deformação obtida no ensaio de resistência à compressão calculou-se o módulo de elasticidade (E) das argamassas (Eq. A). Utilizou-se o método da tangente do trecho linear-elástico ao adotar os pontos de tensão $\left(\sigma_{20 \%}, \sigma_{80 \%}\right)$ e deformação $\left(\varepsilon_{20 \%}, \varepsilon_{80 \%}\right)$ a $20 \%$ e $80 \%$ do valor de tensão de ruptura.

$$
\mathrm{E}=\frac{\Delta \sigma}{\Delta \varepsilon}=\frac{\sigma_{80 \%}-\sigma_{20 \%}}{\varepsilon_{80 \%}-\varepsilon_{20 \%}}
$$

em que: $\sigma$ é a tensão aplicada (MPa) e $\varepsilon$ a deformação (\%).

Aplicação dos revestimentos: as argamassas da pesquisa foram produzidas para a aplicação sobre paredes de concreto em ambiente industrial, na fábrica de prémoldados. Dessa forma, a aplicação de todos os traços ocorreu com lançamento da argamassa sobre a parede em posição horizontal. Adequando a aplicação ao processo fabril, as paredes não receberam preparos específicos (como chapisco), haja vista a aplicação de argamassa ocorrer logo após a vibração das paredes, ou seja, a aplicação se fez com o concreto ainda fresco. As misturas de argamassa foram vertidas e espalhadas sobre as paredes de concreto e, em seguida, foi realizado o acabamento superficial por meio de desempenadeira. A espessura do revestimento, aplicado em apenas uma face da parede, foi fixada em $3 \mathrm{~cm}$ e foi garantida por meio de gabaritos nas laterais do painel. Assim, o sistema de vedação ficou composto pela parede de concreto, com $10 \mathrm{~cm}$ de espessura, e pelo revestimento de argamassa de $3 \mathrm{~cm}$ de espessura. Avaliação do desempenho dos revestimentos: o programa de ensaios dos revestimentos contemplou a determinação da resistência de aderência à tração, com 12 corpos de prova por situação (ABNT NBR 13528:2010) e a permeabilidade à água, determinada pelo método do cachimbo, com 3 pontos de ensaio por situação analisada, utilizando a metodologia do CSTC NIT 224 [21].

Moldagem de placas de argamassa de revestimento e de concreto: para os ensaios de determinação de condutividade térmica foram moldadas duas placas $(28 \times 28 \times 3,2 \mathrm{~cm})$ de cada argamassa. Para a mesma finalidade, procedeu-se a moldagem também de duas placas de concreto com as mesmas características do utilizado na parede em estudo. Ademais, para cada argamassa estudada foi moldada uma placa de revestimento $(28 \times 17 \times 2 \mathrm{~cm})$ para realização de avaliação da durabilidade do compósito por meio de ciclos de molhagem e secagem. Ciclos de molhagem e secagem: a molhagem se deu pela imersão das placas de revestimento em água em temperatura ambiente por um dia e posteriormente a secagem a $60^{\circ} \mathrm{C}$ em estufa com ventilação forçada durante 6 dias. Após cada ciclo, verificou-se a massa e o aspecto visual das placas por meio de inspeção visual detalhada. Foi realizado um total de 14 ciclos ininterruptos; posteriormente procedeu-se a realização de mais quatro ciclos após intervalo de 59 semanas (sem realização de ciclos). Os equipamentos utilizados nesta etapa foram: estufa da Ethiktechnology, 420-8TD 200, e balança eletrônica digital microprocessada de precisão decimal 0,1 g (markL10001). Determinação da condutividade térmica: com as placas de $28 \times 28 \times 3,2$ $\mathrm{cm}$ moldadas com as argamassas de revestimento (REF, E80 e E90LV) e com o concreto das paredes pré-moldadas, foram realizados os ensaios de condutividade térmica. $\mathrm{O}$ procedimento utilizado consta do método de determinação da condutividade térmica pelo princípio da placa quente protegida, prescrito na norma ABNT NBR 152204:2005 [22]. Para essa determinação utilizou-se forno de condutividade térmica da Unidigital, PE 0877-0213, capaz de fornecer precisão de três casas decimais. Cálculos térmicos e verificação dos níveis mínimos de desempenho térmico: a verificação dos níveis mínimos de desempenho térmico do sistema de vedação externa de parede de concreto revestida com argamassa foi efetuada segundo o procedimento das normas ABNT NBR 15575-4:2013 [7] e ABNT NBR 152202:2005 [23]. O procedimento 1 simplificado da norma de desempenho estabelece os valores máximos admissíveis para a transmitância térmica (U) e os valores mínimos para a capacidade térmica $\left(\mathrm{C}_{\mathrm{T}}\right)$ das paredes externas. Os cálculos foram efetuados conforme a NBR 15220-2, Eqs. B a E. Para tanto, os valores de condutividade térmica dos materiais (argamassas e concreto) foram obtidos por meio de ensaio normalizado pela ABNT NBR 15220-4:2005.

$$
\begin{aligned}
& \mathrm{R}_{\mathrm{T}}=\frac{\mathrm{e}_{\text {concreto }}}{\lambda_{\text {concreto }}}+\frac{\mathrm{e}_{\text {argamassa }}}{\lambda_{\text {argamassa }}} \\
& \mathrm{R}_{\mathrm{T}}=\mathrm{R}_{\text {se }}+\mathrm{R}_{\mathrm{t}}+\mathrm{R}_{\mathrm{si}} \\
& \mathrm{U}=\frac{1}{\mathrm{R}_{\mathrm{T}}} \\
& \mathrm{CT}=(\text { e.c. } \rho)_{\text {concreto }}+(\text { e.c. } \rho)_{\text {argamassa }}
\end{aligned}
$$

em que: $R_{t}$ é a resistência térmica da parede $\left(\mathrm{m}^{2} . \mathrm{K} / \mathrm{W}\right)$, e a espessura do material $(\mathrm{m}), \lambda$ a condutividade térmica do material $[\mathrm{W} /(\mathrm{m} \cdot \mathrm{K})], \mathrm{R}_{\mathrm{T}}$ resistência térmica total $\left(\mathrm{m}^{2} . \mathrm{K} / \mathrm{W}\right)$, $\mathrm{R}_{\mathrm{se}}$ a resistência superficial externa $\left(\mathrm{m}^{2} \cdot \mathrm{K} / \mathrm{W}\right), \mathrm{R}_{\mathrm{si}}$ a resistência superficial interna $\left(\mathrm{m}^{2} . \mathrm{K} / \mathrm{W}\right), \mathrm{U}$ a transmitância térmica $\left[\mathrm{W} /\left(\mathrm{m}^{2} \cdot \mathrm{K}\right)\right], \mathrm{C}_{\mathrm{T}}$ a capacidade térmica $\left(\mathrm{kJ} / \mathrm{m}^{2} . \mathrm{K}\right)$, c o calor específico do material [J/(kg.K)] e @ a densidade de massa aparente $\left(\mathrm{kg} / \mathrm{m}^{3}\right)$.

\section{RESULTADOS E DISCUSSÃO}

Caracterização do resíduo $L V$ : a caracterização química do resíduo de fibras e vermiculita por meio de FRX é apresentada na Tabela V. Observou-se que o material foi composto essencialmente por sílica, seguido de óxido de cálcio e alumina, mesmos compostos químicos que constituem os demais materiais das argamassas (cimento, cal e areia). A Fig. 4 apresenta micrografias para medidas de diâmetro de fibras e o aspecto da vermiculita e das fibras componentes do resíduo. Observou-se que os grãos de 
vermiculita foram maiores do que as fibras de lã de rocha e lã de vidro e que a distinção entre os tipos de fibras somente pela análise visual não foi possível. A análise das imagens obtidas no MEV permitiu determinar as dimensões das fibras, as quais apresentaram comprimento médio de 453,5 $\mu \mathrm{m}$ e diâmetro médio de 6,9 $\mu \mathrm{m}$ (amostragem de 25 filamentos). Com base nestas dimensões foi obtido um fator de forma (razão de aspecto) igual a 65,6. O que caracteriza um reforço fibroso é o fato de possuir comprimento muito maior que a sua dimensão na seção transversal. $\mathrm{O}$ aumento de resistência geralmente está associado a essa característica de alta razão de aspecto das fibras possibilitando transferências de carga [24]. Dessa forma, a razão de aspecto obtida permite indicar potencialidade das fibras LV como reforço fibroso para argamassas. O difratograma do resíduo LV é apresentado na Fig. 5. Os principais constituintes identificados na identificação mineralógica foram: vermiculita, cristobalita, tridimita e sílica. Em menores quantidades também se identificou a presença de calcita, tungstenita, ominelita e andalusita. A determinação da massa específica do resíduo $\mathrm{LV}$, pelo método de picnometria a gás hélio, resultou em valor médio de $2,46 \mathrm{~g} / \mathrm{cm}^{3}$.

Avaliação das argamassas: os resultados obtidos para as argamassas no estado fresco estão apresentados na Tabela VI. O decréscimo do índice de consistência é explicado pela inserção de resíduos de poliestireno expandido (EPS) que influenciam reduzindo a fluidez da argamassa $[19,20]$; as fibras também contribuem para a alteração da trabalhabilidade à medida que aumentam a coesão das argamassas por meio do mecanismo de ancoragem que, apesar de reduzir o índice de consistência, promove melhorias mecânicas devido ao fator de forma [24]. A geometria dos resíduos de EPS (triturados) e das fibras também minora a plasticidade do material $[25,26]$. Apesar disto, a utilização das argamassas com resíduos não foi prejudicada já que a aplicação do revestimento foi realizada com as paredes na horizontal, de acordo com o processo industrial adotado pelo fabricante dos pré-moldados. Os valores de densidade de massa no estado fresco indicaram a leveza propiciada às argamassas com inserção dos resíduos.

A Fig. 6 apresenta o aspecto de acabamento das argamassas e seu interior (imagens posteriores ao ensaio de tração na flexão). Os resultados de caracterização obtidos para as argamassas no estado endurecido são apresentados na Tabela VII. A maioria das propriedades foi afetada pela substituição da areia pelos resíduos leves, como comprovaram Passos et al. [18]. Ao explicarem a redução da resistência à compressão, os autores obtiveram coeficiente de determinação $\left(\mathrm{R}^{2}\right)$ próximo a 1,0 ao relacionar com o aumento do teor de EPS a queda da resistência à compressão. Esse parâmetro é afetado pela incorporação dos resíduos menos resistentes que facilitam a propagação de fissuras pelo material [27]. Outros autores analisaram por microtomografia de raios $\mathrm{X}(\mu \mathrm{CT})$ a estrutura de vazios em argamassas leves e contribuíram, assim, para a compreensão das propriedades mecânicas destes materiais [17]. Ressaltase, como indicam estes estudos, que a natureza hidrofóbica das partículas de EPS aumenta a relação água/cimento no entorno dos grãos de EPS, explicando a zona de transição entre as fases em argamassas com EPS, que facilita

Tabela V - Caracterização do resíduo LV por FRX (\% massa).

[Table V - Characterization of LV waste by XRF (wt\%).]

\begin{tabular}{cccccccccc}
\hline $\mathrm{SiO}_{2}$ & $\mathrm{CaO}$ & $\mathrm{Al}_{2} \mathrm{O}_{3}$ & $\mathrm{MgO}$ & $\mathrm{Fe}_{2} \mathrm{O}_{3}$ & $\mathrm{SO}_{3}$ & P.F. & $\mathrm{Na}_{2} \mathrm{O}^{\mathrm{a}}$ & $\mathrm{K}_{2} \mathrm{O}^{\mathrm{a}}$ & Equiv. alcalino \\
\hline 43,15 & 16,07 & 10,04 & 7,23 & 6,65 & - & 10,71 & 3,38 & 1,70 & 4,50 \\
\hline
\end{tabular}

a -álcalis totais.
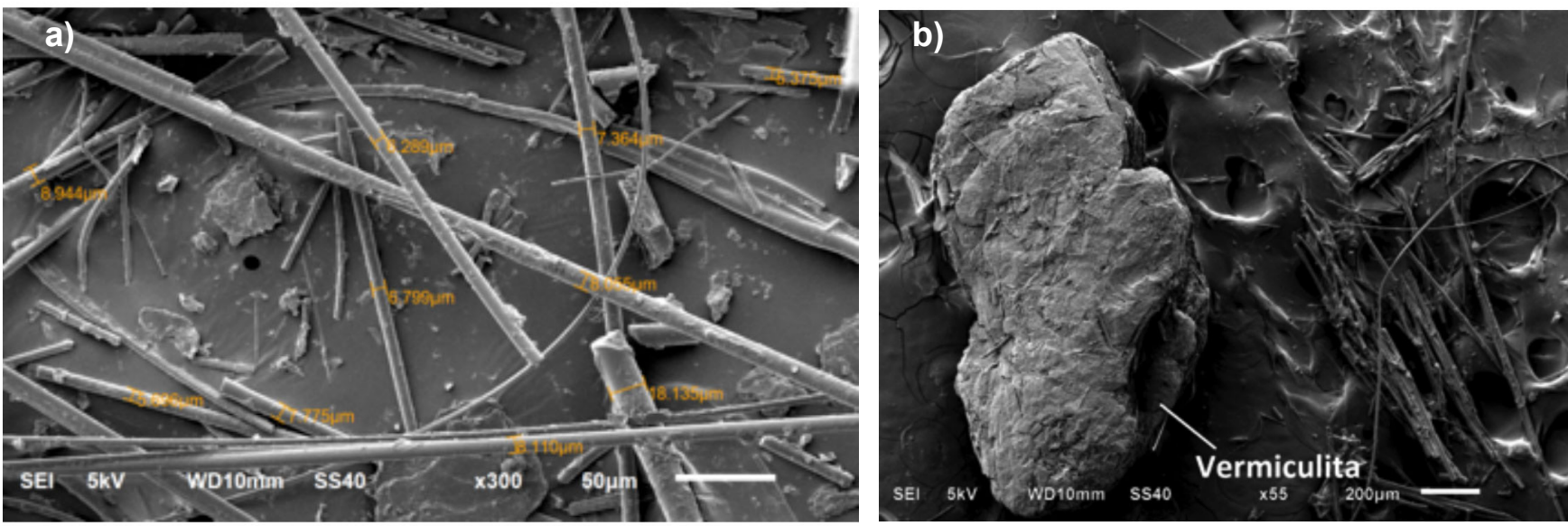

Figura 4: Micrografias de MEV mostrando: a) imagem típica usada para as medidas de diâmetro para determinação do fator de forma das fibras; e b) aspecto de grão de vermiculita e das fibras que constituem o resíduo de lixamento de painéis isolantes.

[Figure 4: SEM micrographs showing: a) typical image used for measurement of diameters and determination of aspect ratio of the fibers; and $b$ ) shape of vermiculite and fibers in the waste from thermoacoustic insulation panels.] 


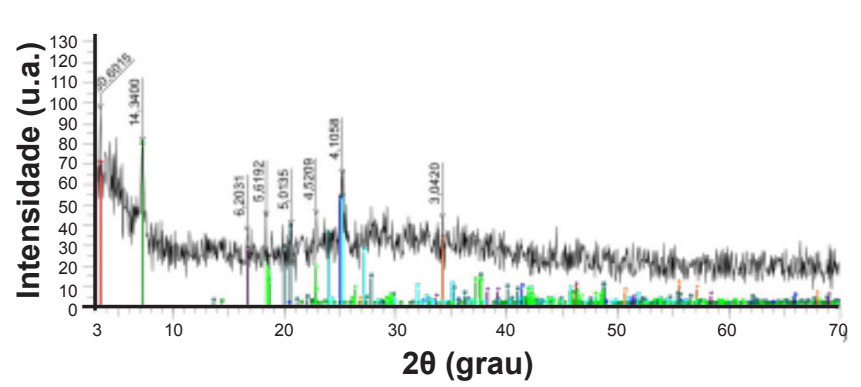

ㄱ.] 755.20160 - Co - File: 755.2016 - Co.raw - Type:2Th/Th loc

- 01-074-1732 (I) - Vermiculite-2M - $\mathrm{Mg}_{3} \mathrm{Si}_{4} \mathrm{O}_{10}(\mathrm{OH})_{2}$

- 01-085-0621 (I) Cristobalite - $\mathrm{SiO}$

- 01-058-0344 (N) - Silicon Oxide - SiO

- 01-001-0837 (D) - Calcite - $\mathrm{CaCO}_{3}$

- 01-070-8525 (*) -Ominelite - $\left(\mathrm{Fe}_{0.927} \mathrm{Mg}_{\mathrm{O} .0 .073}\right) \mathrm{Al}_{3} \mathrm{BSiO}_{9}$

- 00-008-0237 (I) - Tungstenite - WS

00-016-0152 (D) - Tridymite - $\mathrm{SiO}_{2}$

01-075-4822 (A) Andalusite - $\mathrm{Al}_{2} \mathrm{SiO}_{5}$

- 01-018-0036(I) - Andalusite, manganian - $(\mathrm{Al}, \mathrm{Mn})_{2}\left(\mathrm{SiO}_{4}\right) \mathrm{O}$

Figura 5: Difratograma de raios $X$ do resíduo LV.

[Figure 5: X-ray diffraction pattern of LV waste.]

Tabela VI - Caracterização das argamassas - estado fresco. [Table VI - Mortar's fresh properties.]

\begin{tabular}{lcccc}
\hline & REF & E80 & E90 & E90LV \\
\hline $\begin{array}{l}\text { Relação água/materiais } \\
\text { secos (kg/kg) }\end{array}$ & 0,18 & 0,39 & 0,55 & 0,48 \\
$\begin{array}{l}\text { Relação água/ } \\
\text { aglomerante (kg/kg) }\end{array}$ & 1,12 & 0,85 & 0,97 & 0,87 \\
$\begin{array}{l}\text { Relação água/cimento } \\
\text { (kg/kg) }\end{array}$ & 1,88 & 1,07 & 1,24 & 1,13 \\
$\begin{array}{l}\text { Consistência média } \\
\text { (mm) }\end{array}$ & 255 & 167 & 153 & 140 \\
$\begin{array}{l}\text { Densidade de massa } \\
\text { média }\left(\mathrm{kg} / \mathrm{m}^{3}\right)\end{array}$ & 1868 & 770 & 628 & 729 \\
\hline
\end{tabular}

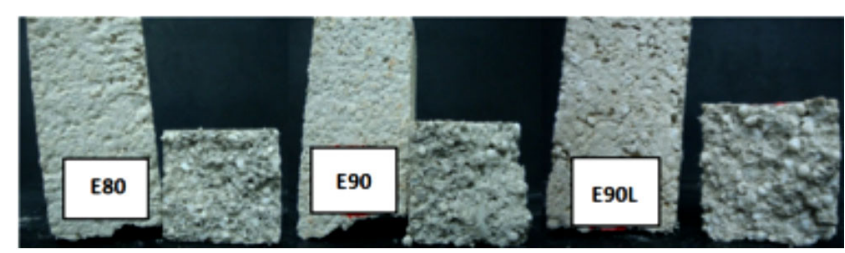

Figura 6: Aspecto do acabamento das argamassas.

[Figure 6: Finishing appearance of mortars.] consideravelmente a propagação de fissuras [20]. Ademais, não se pode esquecer que as argamassas com resíduo têm a substituição em volume de areia por EPS superior a 80\%; logo, se a resistência das rochas empregadas na construção geralmente é superior a $100 \mathrm{MPa}$ [28] e a resistência do material EPS não supera 0,4 $\mathrm{MPa}$ [12], não podem ser esperadas resistências altas na argamassa com resíduo. No entanto, a menor resistência à compressão se comparada ao traço de referência não é um problema, pois os revestimentos de argamassa não são solicitados durante sua vida útil por esforços de compressão [4].

O gráfico tensão-deformação (Fig. 7a) demonstrou que, além de menos resistente, as argamassas leves apresentaram menor módulo de elasticidade. Este por sua vez é um interessante ganho, pois indica a maior possibilidade de deformação do material sem ruptura do revestimento. Os revestimentos estão sujeitos a movimentações diferenciais e diversas solicitações que demandam do material uma adequada deformabilidade. Um comportamento atípico para os materiais convencionais foi encontrado prosseguindo-se o ensaio de compressão das argamassas leves após a ruptura. O gráfico da Fig. 7b apresenta o desenvolvimento da tensão aplicada com a redução dos vazios de EPS, sem que a argamassa perca capacidade de suportar a aplicação de carga. Após a continuidade do ensaio verificou-se a redução da altura dos corpos de prova para os traços com EPS (Fig. 8).

Conforme esperado, a resistência à tração na flexão também foi inferior para as argamassas com resíduos, quando comparada com o traço de referência. Entretanto, vale ressaltar que a escolha da adição também de resíduos fibrosos foi baseada no objetivo de aumentar a resistência à tração de argamassas, ensaiadas em um estudo piloto que precedeu a presente pesquisa [25]. Os resíduos de fibras reforçaram o compósito explicando um aumento de $60 \%$ na resistência à tração comparada aos traços que só utilizaram o EPS. A incorporação de resíduos LV contribuiu com o aumento da resistência à tração e à compressão quando se compara o traço E90 com o traço E90LV. Esses resultados reforçam estudos anteriores que apontaram melhorias após a inserção de resíduos fibrosos e também de pesquisas que avaliaram individualmente a incorporação de resíduos de lã de rocha ou lã de vidro às argamassas [6, 26, 29-32]. O aumento da resistência à tração pode contribuir significativamente com o desempenho em longo prazo do revestimento uma vez que

Tabela VII - Caracterização das argamassas - estado endurecido (valores médios).

[Table VII - Properties of hardened mortars (average values).]

\begin{tabular}{lcccc}
\hline & REF & E80 & E90 & E90LV \\
\hline Resistência à compressão RC (MPa) & 4,13 & 1,10 & 0,70 & 1,19 \\
Resistência à tração na flexão RT (MPa) & 1,78 & 0,88 & 0,71 & 1,16 \\
Relação RT/RC & 0,43 & 0,80 & 1,01 & 0,97 \\
Módulo de elasticidade $(\mathrm{GPa})$ & 4,87 & 1,23 & 0,46 & 0,55 \\
Densidade aparente $\left(\mathrm{kg} / \mathrm{m}^{3}\right)$ & 1707 & 654 & 490 & 604 \\
Coeficiente de capilaridade $\left(\mathrm{g} / \mathrm{dm}^{2} \cdot \mathrm{min}^{1 / 2}\right)$ & 13,08 & 1,17 & 2,73 & 0,73 \\
\hline
\end{tabular}



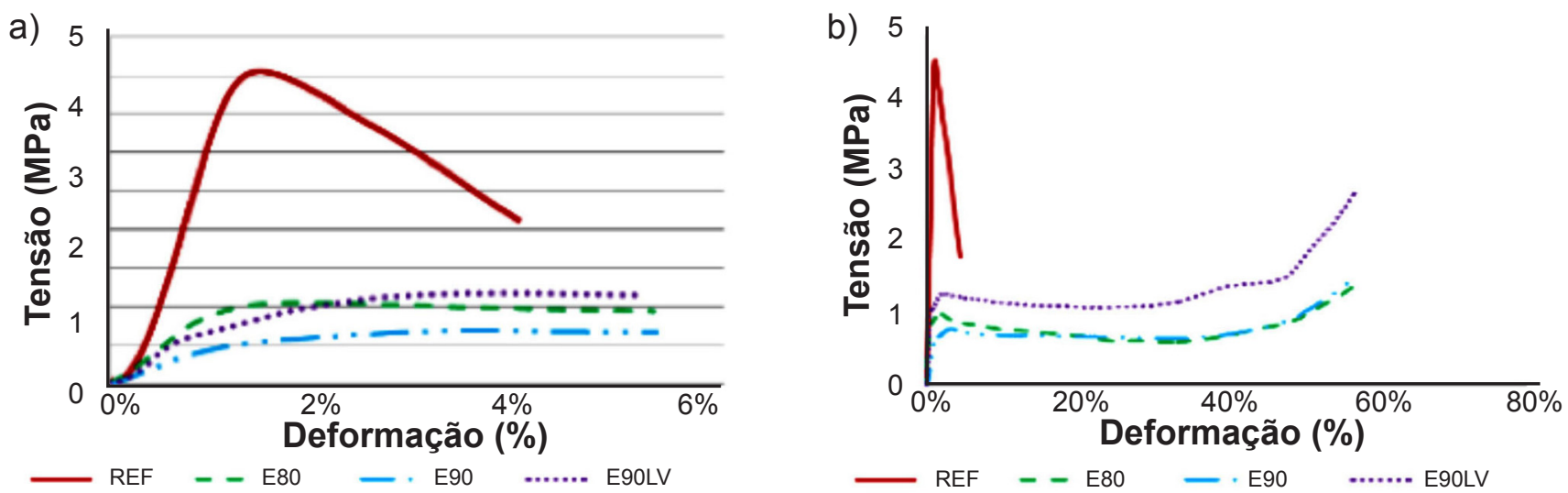

Figura 7: Gráficos tensão x deformação em compressão na faixa de baixa deformação (a) e ensaio completo (b).

[Figure 7: Stress-strain curves in compression in the region of low strain (a) and full test (b).]

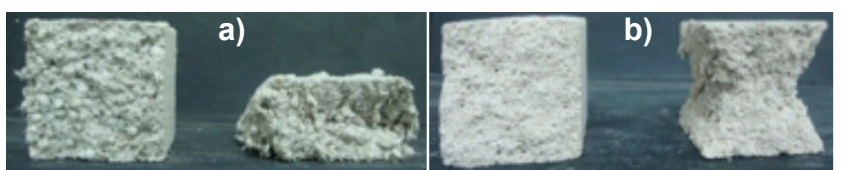

Figura 8: Aspecto da amostra antes e após ensaio de resistência à compressão: (a) E90LV; e (b) REF.

[Figure 8: Sample images before and after compressive strength test: (a) E90LV; and (b) REF.]

influencia no combate à fissuração.

A densidade de massa aparente no estado endurecido, assim como no estado fresco, confirmou os resultados esperados com a inserção de resíduos de EPS. A incorporação do resíduo leve em substituição à areia reduziu os valores dessa propriedade. Entretanto, notou-se a densificação (E90LV) a partir da adição do resíduo LV que se somou aos materiais constituintes do traço E90 proporcionando maior massa e coesão. Os resultados do ensaio de capilaridade (Tabela VII) demonstraram a vantagem da utilização das argamassas elaboradas com os resíduos e polímero. Os efeitos observados corroboram estudos anteriores e são explicados pela utilização de aditivo de base acrílica $[16,21]$. Vale ressaltar também o caráter hidrofóbico das partículas de EPS.

Avaliação do desempenho dos revestimentos: os resultados de resistência de aderência à tração dos revestimentos aplicados sobre as placas pré-moldadas de concreto estão mostrados na Tabela VIII. Observou-se, conforme esperado, que as argamassas com substituição de areia pelo EPS apresentaram menores valores de resistência de aderência, devido à baixa resistência mecânica intrínseca do EPS. No entanto, apesar desses valores parecerem preocupantes em uma primeira análise, deve-se observar que para as argamassas com maiores teores de resíduos todas as rupturas no ensaio foram do tipo coesiva (no interior da argamassa), não se caracterizando por ter sido medida a aderência e sim a resistência à tração da argamassa. As prescrições francesa [33] e portuguesa LNEC 2005 [34] estabelecem que, para revestimentos externos, o valor mínimo deve ser igual ou superior a $0,30 \mathrm{MPa}$ apenas quando as rupturas não são de natureza coesiva. Ou seja, a exigência de valor mínimo referese apenas a revestimentos que apresentam rupturas adesivas, que são as mais perigosas do ponto de vista de potencial para a patologia [35]. Ademais, a respeito dos resultados do ensaio de aderência cabe uma reflexão sobre as tensões que existem efetivamente nos revestimentos aplicados, às quais a resistência de aderência deve se opor. As tensões de cisalhamento podem ser calculadas pela Eq. F:

$$
\mathrm{T}_{\mathrm{C}}=\frac{(\text { E.c.e) }}{\mathrm{A}}
$$

em que: Tc é a tensão de cisalhamento, E o módulo de elasticidade, $\varepsilon$ a movimentação do revestimento, e a espessura do revestimento e A a área de contato. Uma vez que os revestimentos convencionais (representados nesta pesquisa pelo REF, com 4,87 GPa) têm módulo de elasticidade mais alto do que os revestimentos elaborados com EPS, as tensões de cisalhamento são também muito superiores no revestimento convencional. Os revestimentos com EPS, principalmente os com $90 \%$ de substituição da areia, apresentam tensões muito baixas. Além disso, o peso próprio dos revestimentos com EPS é muito baixo, não solicitando a interface argamassa/substrato ao longo

Tabela VIII - Resultados de resistência de aderência.

[Table VIII - Bond strength results.]

\begin{tabular}{lcccc}
\hline & REF & E80 & E90 & E90LV \\
\hline Média (MPa) & $\geq 0,38$ & $\geq 0,19$ & $>0,07$ & $>0,13$ \\
Desvio padrão $(\mathrm{MPa})$ & 0,21 & 0,05 & 0,03 & 0,06 \\
Tipo de ruptura & $17 \%$ i-83\% a & $17 \%$ i-83\% a & $100 \%$ a & $100 \%$ a \\
\hline i- ruptura na interface argamassa/concreto; a - ruptura no interior da argamassa. & &
\end{tabular}


de sua vida útil. Distingue-se ainda que a incorporação de resíduos fibrosos proporcionou um aumento dos valores de resistência de aderência à tração do revestimento, quando comparadas as argamassas E90 e E90LV. O aumento da resistência à tração na flexão é explicado pela adição das fibras (LV) como comprovado neste estudo e também em estudo de caracterização específico do resíduo com vistas à adição em argamassas e concretos [25]. Em contraposição, fibras de polipropileno (razão de aspecto superior a 400) não apresentam influência significativa sobre a resistência de aderência à tração em argamassas convencionais, também explicada pela diminuição da resistência à tração na flexão em argamassas com adição desta fibra [36].

A avaliação da argamassa (enquanto material, corpos de prova) indicou bons resultados quanto à capilaridade. No entanto, mais importante é a avaliação do sistema, revestimento aplicado às placas pré-moldadas, tendose dessa forma uma informação quanto ao desempenho (estanqueidade). Para a avaliação da permeabilidade e absorção de água do sistema de revestimento utilizou-se o método do cachimbo. Os resultados médios obtidos nesse experimento estão apresentados na Fig. 9. Ficou confirmado o excelente desempenho dos revestimentos aplicados cujas argamassas foram elaboradas com os resíduos e polímero quando comparadas à argamassa de referência.

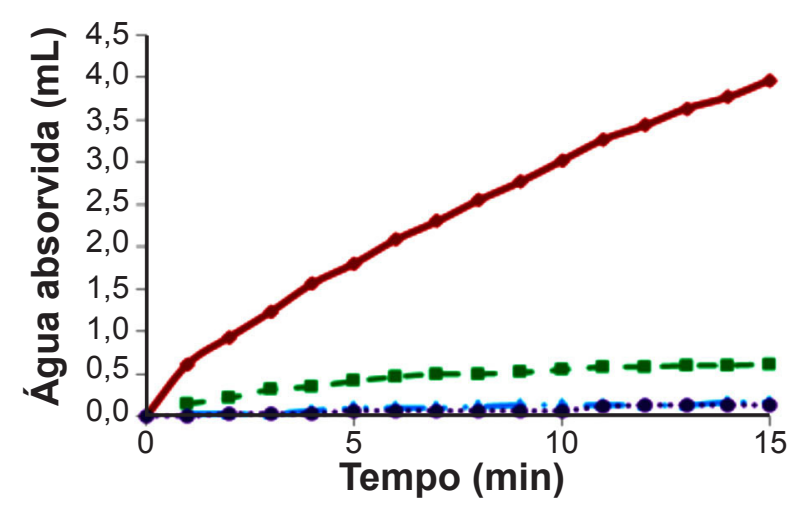

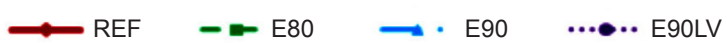

Figura 9: Resultados do ensaio de absorção de água do revestimento pelo método do cachimbo.

[Figure 9: Absorption test results by NIT 224 - CSTC, 2002.]

Relativo à avaliação da durabilidade por meio de ciclos de molhagem e secagem, as argamassas com os resíduos apresentaram comportamento similar de variação de massa ao da argamassa de referência após os 18 ciclos, indicando potencial para sua utilização em revestimentos externos (Fig. 10). As placas de argamassa também foram avaliadas visualmente após a conclusão de cada ciclo e nenhuma apresentou qualquer indício de deterioração, tais como fissuração, pulverulência, formação de vesículas, etc. Cabe aqui destaque de uma preocupação específica com a placa moldada com a argamassa E90LV. Isto porque esta argamassa contém fibras de lã de vidro (compostas por cristobalita e tridimita, identificadas por DRX), que poderiam apresentar deterioração pelo ataque dos álcalis presentes na matriz cimentícia. Atribui-se em parte a não existência das reações álcali-agregado à contribuição da emulsão polimérica utilizada, bem como ao tamanho das partículas envolvidas. Esta argamassa não apresentou qualquer vestígio de degradação após mais de um ano de observação e 18 ciclos de molhagem e secagem.

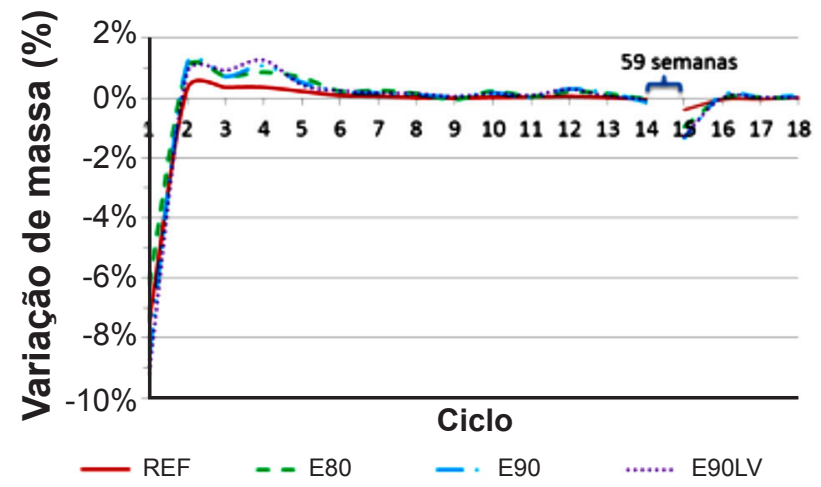

Figura 10: Gráfico de variação de massa de argamassas expostas a ciclos de durabilidade.

[Figure 10: Mass variation graph for mortars exposed to durability cycles.]

Verificação dos níveis mínimos de desempenho térmico: na Tabela IX estão apresentados os valores de condutividade térmica determinados experimentalmente (pelo método de ensaio da placa quente protegida) bem como obtidos conforme ABNT NBR 15220-2:2005, anexo B. Notouse que os valores de condutividade térmica obtidos pelos dois métodos (experimental e tabelas ABNT) foram bem diferentes, mesmo para os materiais convencionais (concreto e argamassa de referência). O método da ABNT levou a valores maiores do que os obtidos experimentalmente. Os valores obtidos pelo método da placa quente no presente trabalho foram compatíveis com os encontrados por outros autores para argamassas convecionais [16]. Tal fato evidencia a necessidade de cautela ao se utilizar os valores propostos pela norma da ABNT, que por vezes pode superestimar o parâmetro de condutividade térmica. Quando se empregam as Eqs. B a E para a parede de concreto com $10 \mathrm{~cm}$ de espessura revestida com argamassa $(3 \mathrm{~cm})$, utilizando os valores de condutividade térmica obtidos experimentalmente (placa quente), obtêm-se os parâmetros térmicos apresentados na Tabela X. Estes parâmetros permitem uma caracterização prévia do sistema de vedação vertical externa - SVVE, em avaliação, com as diferentes argamassas de revestimento.

Comparando-se os resultados obtidos com os parâmetros prescritos na ABNT NBR 15575-4:2013, mostrados na Tabela XI, os sistemas avaliados com as três argamassas se mostraram adequados quanto à capacidade térmica, ou seja, todos foram superiores a $130 \mathrm{~kJ} / \mathrm{m}^{2} . \mathrm{K}$. Estes resultados são preponderantemente devidos à elevada capacidade térmica da parede de concreto maciça, sendo portanto esta propriedade pouco influenciada pelo revestimento com pequena espessura, como é o caso em questão. Ao se analisar 
Tabela IX - Condutividade térmica (W/m.K).

[Table IX - Thermal conductivity (W/m.K).]

\begin{tabular}{lccccc}
\hline & Concreto & REF & E80 & E90 & E90LV \\
\hline $\begin{array}{l}\text { Ensaio placa } \\
\text { quente protegida }\end{array}$ & 1,19 & 0,66 & 0,17 & - & 0,14 \\
$\begin{array}{l}\text { Anexo B ABNT } \\
\text { NBR 15220-2 }\end{array}$ & 1,75 & 1,15 & 0,40 & 0,20 & 0,25 \\
\hline
\end{tabular}

Tabela X - Parâmetros de caracterização térmica.

[Table X - Parameters for thermal characterization.]

\begin{tabular}{lccc}
\hline & REF & E80 & E90LV \\
\hline $\begin{array}{l}\text { Resistência térmica da parede } \\
{\left[\left(\mathrm{m}^{2} . \mathrm{K}\right) / \mathrm{W}\right]}\end{array}$ & 0,13 & 0,27 & 0,31 \\
$\begin{array}{l}\text { Resistência térmica total } \\
{\left[\left(\mathrm{m}^{2} . \mathrm{K}\right) / \mathrm{W}\right]}\end{array}$ & 0,30 & 0,44 & 0,48 \\
$\begin{array}{l}\text { Transmitância térmica }\left[\mathrm{W} /\left(\mathrm{m}^{2} \cdot \mathrm{K}\right)\right] \\
\text { Capacidade térmica }\left[\mathrm{kJ} /\left(\mathrm{m}^{2} \cdot \mathrm{K}\right)\right]\end{array}$ & 3,33 & 2,29 & 2,10 \\
& 254,2 & 230,0 & 223,0 \\
\hline
\end{tabular}

o parâmetro de transmitância térmica de paredes externas, o sistema de revestimento com argamassa referência não atendeu totalmente o critério para todas as zonas bioclimáticas brasileiras; ele atenderia os requisitos mínimos de desempenho térmico das zonas 3 a 8, desde que recebesse pintura com cores claras (absortância inferior a 0,6). Neste caso, as argamassas leves contendo resíduos permitem que os SVVE em parede de concreto atendam aos critérios sem restrições. Esses sistemas possuem valores de transmitância térmica inferiores a $2,5 \mathrm{~W} / \mathrm{m}^{2} . \mathrm{K}$ e assim atenderam os requisitos mínimos para todo território nacional, sem restrição de cor do acabamento, em conformidade com a norma de desempenho.

A variação da espessura do revestimento modifica a caracterização dos principais parâmetros considerados na norma de desempenho. A Fig. 11 mostra a influência da espessura dos revestimentos estudados na transmitância térmica. A partir do gráfico é possível inferir que as argamassas desenvolvidas com incorporação de resíduos

Tabela XI - Critérios de desempenho térmico mínimo da ABNT NBR 15575-4:2013.

[Table XI - Minimum thermal performance criteria - ABNT NBR 15575-4:2013.]

\begin{tabular}{|c|c|c|}
\hline \multicolumn{3}{|c|}{ Transmitância térmica - U (W/m².K) } \\
\hline Zonas 1 e 2 & \multicolumn{2}{|c|}{ Zonas 3 a 8} \\
\hline \multirow{2}{*}{$\mathrm{U} \leq 2,5$} & $\alpha \leq 0,6$ & $\alpha>0,6$ \\
\hline & $\mathrm{U} \leq 3,7$ & $\mathrm{U} \leq 2,5$ \\
\hline \multicolumn{3}{|c|}{ Capacidade térmica - CT $\left(\mathrm{kJ} / \mathrm{m}^{2} . \mathrm{K}\right)$} \\
\hline Zona 8 & \multicolumn{2}{|c|}{ Zonas 1 a 7} \\
\hline Sem exigência & \multicolumn{2}{|c|}{$\mathrm{CT} \leq 130$} \\
\hline
\end{tabular}

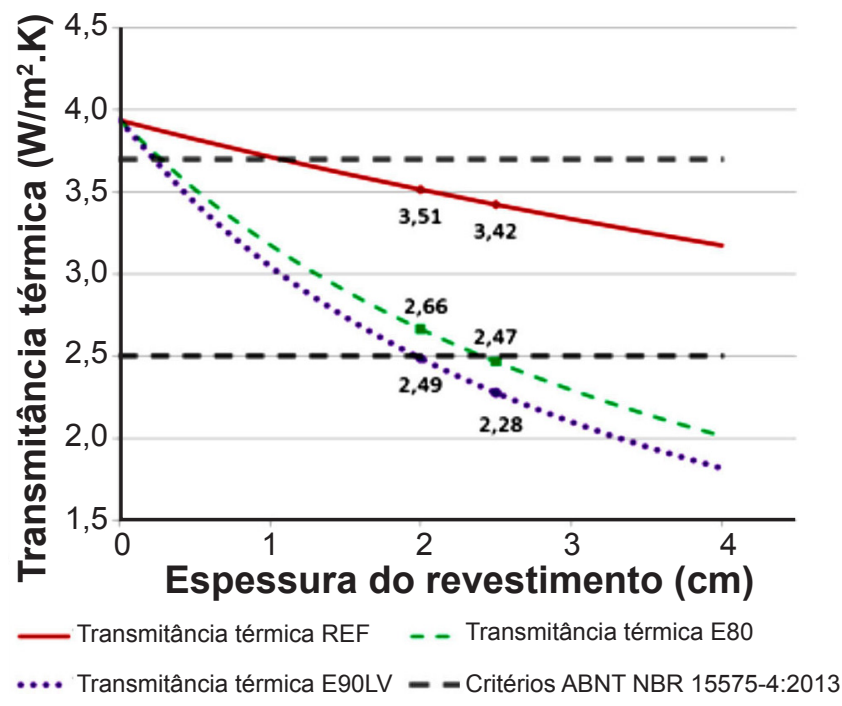

Figura 11: Transmitância térmica em função da espessura do revestimento.

[Figure 11: Thermal transmittance versus plastering mortar thickness.]

atenderam ao critério de transmitância térmica inferior a $2,5 \mathrm{~W} / \mathrm{m}^{2} . \mathrm{K}$, sendo aplicável a todas as zonas bioclimáticas brasileiras a partir de $2,5 \mathrm{~cm}$ de espessura. Entretanto, o sistema convencional (parede de concreto com argamassa REF), mesmo com revestimento de espessuras superiores a do presente estudo $(3 \mathrm{~cm})$, não atenderia o parâmetro mais restritivo de requisito mínimo de desempenho para todas as regiões do país sem restrição do tipo de pintura, influenciado pelo parâmetro de absorbância solar. Somente a partir de 9 $\mathrm{cm}$ de espessura, inviável na prática, o revestimento com argamassa REF atenderia os parâmetros mais restritivos de transmitância térmica.

\section{CONCLUSÕES}

A partir dos ensaios e análises realizadas concluiu-se que as argamassas contendo os resíduos avaliados apresentaram grande potencial para utilização como revestimento isolante térmico de paredes maciças de concreto pré-moldadas. $\mathrm{O}$ revestimento elaborado com a argamassa contendo cerca de $90 \%$ de substituição de areia por poliestireno expandido (EPS) reciclado e o resíduo fibroso (LV) foi considerado o mais adequado do ponto de vista dos parâmetros térmicos, principalmente quanto à transmitância térmica. Ademais, o revestimento com essa argamassa apresentou comportamento adequado quanto a outros parâmetros de desempenho (estanqueidade, aderência e durabilidade) indicando o potencial para utilização em sistemas de vedação externa. Observou-se grande vantagem em associar o resíduo da produção de placas isolantes termoacústicas (composto de lã de rocha, lã de vidro e vermiculita expandida) às argamassas com o EPS reciclado. Isto porque as lãs de rocha e de vidro são fibras minerais que contribuem com o aumento da resistência à tração do compósito e, desta forma, contribuem também com a resistência de aderência do revestimento. A caracterização desse resíduo (LV) mostrou que é constituído 
essencialmente de sílica (nas formas cristalinas tridimita e cristobalita), seguida de óxidos de cálcio e alumínio. Apesar da presença de tridimita e cristobalita, essas fibras não mostraram comportamento deletério em contato com os álcalis da pasta de cimento. As fibras contidas nesse resíduo possuíram dimensões médias de $454 \mu \mathrm{m}$ de comprimento e $7 \mu \mathrm{m}$ de diâmetro, portanto, fator de forma superior a 65 , apresentando características adequadas como de reforço fibroso para argamassas. Com o desenvolvimento dessa argamassa, contribui-se de forma efetiva para a otimização do desempenho térmico de habitações que utilizam o sistema executivo de paredes de concreto maciça pré-moldada. Apresenta-se, assim, uma estratégia mitigadora de impactos causados pela construção civil, uma vez que a argamassa proposta incorpora grande volume de resíduos e que estes substituem a maior parte dos agregados, propiciando a redução da extração de areia natural.

\section{AGRADECIMENTOS}

Os autores agradecem à Coordenação de Aperfeiçoamento de Pessoal de Nível Superior (CAPES) e ao Conselho Nacional de Desenvolvimento Científico e Tecnológico (CNPq) pelas bolsas dos pesquisadores, mestrado e PQ, respectivamente. Agradecem também pelo apoio em ensaios do Laboratório Multiusuário de Microscopia de Alta Resolução (LabMic - UFG), do DCT.T Eletrobras Furnas e do Laboratório de Ensaios em Durabilidade dos Materiais (LEDMa) da Escola Politécnica da UFBA. Por fim, agradecem à UNOTECH, empresa em que foram produzidos as placas pré-moldadas e os revestimentos.

\section{REFERÊNCIAS}

[1] Brasil, Decr. Lei n ${ }^{\circ} 4.059$, "Regulamenta a Lei no 10.295, 17/10/2001 e dá outras providências" (2001).

[2] Brasil, Lei $\mathrm{n}^{\circ} 10.295$, "Dispõe sobre a política nacional de conservação e uso racional de energia e dá outras providências" (2001).

[3] R. Lamberts, L. Dutra, F.O.R. Pereira, "Eficiência energética na arquitetura", Procel, Rio Janeiro (2012).

[4] H. Carasek, in: Materiais de construção civil e princípios de ciência e engenharia de materiais, Org. G.C. Isaia, $2^{\mathrm{a}}$ ed., IBRACON, S. Paulo (2010).

[5] R.M. Apolônio, L.G. Omar, M.C.J.A. Nogueira, B.C. Carvalho, in: Anais $13^{\circ}$ Enc. Nac. Tecn. Amb. Constr., ANTAC, Canela (2010).

[6] H. Shoukry, M.F. Kotkata, S.A. Abo-El-Eneim, M.S. Morsy, S.S. Shebl, Constr. Build. Mater. 102 (2016) 167.

[7] Ass. Bras. Normas Técn., NBR 15575-4, Edificações habitacionais, desempenho parte 4: sistemas de vedações verticais internas e externas - SVVIE, Rio Janeiro (2013).

[8] V.C.L. Lima Neto, B.A. Furtado, C. Krause, Nota Técn. $\mathrm{n}^{\circ}$ 5, Estimativas do déficit habitacional brasileiro (PNAD 2007-2012), Inst. Pesq. Econ. Apl., Brasília (2013).

[9] R.R. Menezes, J. Farias Filho, H.S. Ferreira, G.A. Neves, H.C. Ferreira, Cerâmica 55, 335 (2009) 263.
[10] V.M. John, in: Materiais de construção civil e princípios de ciência e engenharia de materiais, Org. G.C. Isaia, IBRACON, S. Paulo (2007).

[11] G. Hammond, C. Jones, "Inventory of carbon \& energy", Un. Bath, United Kingdon (2011).

[12] Ass. Bras. Poliest. Exp., "Manual utilização - EPS na construção civil", Pini, S. Paulo (2006).

[13] A.A. Sayadi, J.V. Tapia, T.R. Neizert, G.C. Clifton, Constr. Build. Mater. 112 (2016) 716.

[14] A. Schackow, C. Effting, M.V. Folgueras, S. Güths, G.A. Mendes, Constr. Build. Mater. 57 (2014) 1907.

[15] K. Miled, R. Le Roy, K. Sab, C. Boulay, Mech. Mater. 36 (2004) 1031.

[16] C. Aciu, D.L. Manea, L.M. Molnar, E. Jumate, Proc. Technol. 19 (2015) 498.

[17] M. Lanzón, V. Cnudee, T. de Kock, J. Dewanckele, Constr. Build. Mater. 94 (2015) 817.

[18] P.M. Passos, H. Carasek, G.M. Amaral, in Anais $16^{\circ}$ Enc. Nac. Tecn. Amb. Constr., ANTAC, S. Paulo (2016).

[19] V. Ferrándiz-Mas, E. García-Alcocel, Mater. Construc. 62 (2012) 547.

[20] V. Ferrándiz-Mas, T. Bond, E. García-Alcocel, C.R. Cheeseman, Constr. Build. Mater. 61 (2014) 286.

[21] V. Ferrándiz-Mas, E. García-Alcocel, Constr. Build. Mater. 46 (2013) 175.

[22] Ass. Bras. Normas Técn., NBR 15220-4, "Medição da resistência térmica e da condutividade térmica pelo princípio da placa quente protegida", Rio Janeiro (2005).

[23] Ass. Bras. Normas Técn., NBR 15220-2, "Desempenho térmico de edificações, parte 2: método de cálculo da transmitância térmica, da capacidade térmica, do atraso térmico e do fator solar de elementos e componentes de edificações", Rio Janeiro (2005).

[24] F.L. Matthews, R.D. Rawlings, Composite materials: engineering and science, Chapman Hall, Great Britain (1994).

[25] P.M. Passos, L.L. Chagas, L.D. Feitosa, M.M. Ribeiro, H. Carasek, in: Anais $59^{\circ}$ Congr. Bras. Concr., IBRACON, Bento Gonçalves, (2017) 1.

[26] W. Lin, N. Cheng, R. Huan, S. Zou, Mater. Charact. 84 (2013) 1.

[27] K. Strecker, C.A. Silva, T.H. Panzera, Cerâmica 60, 354 (2014) 310.

[28] P.K. Mehta, P.J.M. Monteiro, Concreto: microestrutura, propriedades e materiais, $2^{\text {a }}$ ed., IBRACON, S. Paulo (2008).

[29] M.G. Medeiros, A.B. Castilho, J.C. Rocha, K.A. Oliveira, in: Anais $5^{\circ}$ Fórum Int. Resíd. Sól., São Leopoldo (2014).

[30] N. Benmasour, B. Agoudjil, A. Gherabli, A. Kareche, A. Boudenne, Energ. Buildings 81 (2014) 98.

[31] N. Evangelista, J.A.S. Tenório, J.R. de Oliveira, Rev. Esc. Minas 65 (2012) 79.

[32] W.C. Fontes, M.B. Dutra, E.M. Okada, G.J.B. Silva, R.A.F. Peixoto, in: Anais $56^{\circ}$ Congr. Bras. Concr., IBRACON, Natal (2014).

[33] Ass. Franç. Normal.,NF EN 1015-21, "Méthodes d'essai 
des mortiers pour maçonneries, partie 21: détermination de la compatibilité des mortiers d'enduit extérieur monocouche avec les supports", France (2003).

[34] Lab. Nac. Eng. Civil, "Regras para concessão de documentos de aplicação a revestimentos pré-doseados de ligante mineral com base em cimento para paredes", Relat. 427/05, NRI, Lisboa (2005).

[35] H. Carasek, Téchne Rev. Tecn. Constr. 185 (2012) 51.

[36] R. Monte, M. Barros, A.D. Figueiredo, in: Anais $4^{\circ}$ Congr. Port. Argam. Constr., Coimbra (2012).

(Rec. 10/11/2017, Rev. 06/04/2018, Ac. 24/05/2018) 